\title{
Tracking of sugar-sweetened soft drinks and other common beverages from infancy to childhood and adolescence
}

\author{
W.L Wrieden ${ }^{1}$, T. Spencer ${ }^{1}$, M.S Pearce ${ }^{1}$, X. Janssen $^{2}$, L. Basterfield ${ }^{1}$, A.R. Jones ${ }^{1}$, J.J Reilly ${ }^{2}$, \\ C.M Wright ${ }^{3}$ and A.J. Adamson ${ }^{1}$ \\ ${ }^{1}$ Institute of Health \& Society, Human Nutrition Research Centre, Newcastle University, Newcastle upon Tyne NE2 \\ $4 H H, U K$, \\ ${ }^{2}$ Physical Activity for Health Group, University of Strathclyde, Glasgow, G1 1QE, UK. and \\ ${ }^{3}$ School of Medicine, Dentistry \& Nursing, Child Health, University of Glasgow, Glasgow, G51 4TF, UK.
}

It is well established that intakes of free sugars by children and adolescents are considerably higher than guidelines (13-14\% vs $5 \%$ of total energy) and that a major contributor to this intake is sugar-containing soft beverages (particularly soft drinks and fruit juice) in 11-18 year olds, where these beverages provide a third of the free sugar. The aim of this work was to determine the degree of tracking of sugar containing soft beverages and other beverages from infancy to childhood and from infancy to mid-adolescence using data from the Gateshead Millennium Study ${ }^{(1)}$.

Beverage intake data of the children were collected using age appropriate methods; postal questionnaires to parents at 30 months ${ }^{(2)}$, the Food Assessment in Schools Tool (FAST) at 7 years ${ }^{(3)}$ and a computer-based self-completion 24 -hour recall INTAKE24 ${ }^{(4)}$ at 15 years. The sample comprised $n=428$ at 30 months, $n=474$ at 7 years and $n=364$ at 15 years. The beverage data were sorted into six categories (soft drinks (non-diet carbonated), fruit juice, squash, diet soft drinks (carbonated and non-carbonated), milk and water). High beverage intake was defined as those in the top $20 \%$ of consumption within the cohort (e.g. at 15 years high intakes of soft drinks (non-diet) carbonated were between $343-3100 \mathrm{ml} / \mathrm{d}$ ) or, for beverages where there were large numbers of non-consumers, (e.g soft drinks at 30 months) into consumers and non-consumers. Associations between high beverage intake at 30 months and high intake at 7 and 15 years were tested using logistic regression, adjusting for potentially confounding factors (gender and a binary measure of socio-economic status (SES) assessed at recruitment in $1999^{(7)}$ ). The reference value for adjusted Odds Ratios (aOR) was low or no intake.

At age $30 \mathrm{~m} 36 \%$ consumed carbonated soft drinks, $47.8 \%$ at age 7 years and $46.7 \%$ aged 15 years. Those 15 year olds who consumed soft drinks, consumed a median $280 \mathrm{~g} /$ day, regardless of SES status.

High intake (or consumption) of soft drinks, fruit juice, diet soft drinks and water at 30 months was significantly associated with high intake at age 7 years but not at 15 years (see table). The adjusted odds ratio for being a soft drink consumer at age 7 years was almost 3 times the reference value of a non-consumer at age 30 months, but when the analysis was stratified for SES this increased to almost 5 times the reference for those of higher SES (OR 4.87 95\% CI 2.34-10.14 P<0.001) compared to those of lower SES where the OR was not significant.

\begin{tabular}{lcccccc}
\hline $\begin{array}{l}7 \text { years } \\
\text { Beverage intake at 30 months }\end{array}$ & $\begin{array}{c}\text { aOR } \\
\text { Soft Drinks }\end{array}$ & $95 \% \mathrm{CI}$ & P-value & $\begin{array}{c}15 \text { years } \\
\text { aOR }\end{array}$ & $95 \%$ CI & P-value \\
$\begin{array}{l}\text { Consumer } \\
\begin{array}{l}\text { Squash } \\
\quad \text { High Intake }\end{array}\end{array}$ & 2.912 & $1.652,5.135$ & $\mathbf{< 0 . 0 0 1}$ & 1.778 & $0.848,3.726$ & 0.128 \\
$\begin{array}{l}\text { Fruit Juice } \\
\quad \text { High Intake }\end{array}$ & 1.443 & $0.754,2.759$ & 0.268 & 1.613 & $0.768,3.384$ & 0.206 \\
$\begin{array}{l}\text { Dist Soft Drinks } \\
\quad \text { Consumer }\end{array}$ & 3.624 & $1.958,6.708$ & $\mathbf{< 0 . 0 0 1}$ & 1.640 & $0.761,3.533$ & 0.207 \\
$\begin{array}{l}\text { Water } \\
\quad \text { High Intake }\end{array}$ & 4.520 & $2.289,8.926$ & $\mathbf{< 0 . 0 0 1}$ & 2.091 & $0.961,4.551$ & 0.063 \\
$\begin{array}{l}\text { Milk } \\
\text { High Intake }\end{array}$ & 2.954 & $1.610,5.420$ & $\mathbf{< 0 . 0 0 1}$ & 1.410 & $0.631,3.151$ & 0.402 \\
& 1.988 & $0.993,3.980$ & 0.053 & 0.991 & $0.452,2.170$ & 0.982 \\
\hline
\end{tabular}

These data suggest that the family environment can protect toddlers and children from excessive exposure to sweetened beverages, but that by adolescence young people are more exposed to external influences.

1. Parkinson KN, Adamson AJ, Basterfield L et al. (2015) Arch Dis Child 100, 779-783.

2. Parkinson KN, Wright C \& Drewett R (2007) Int J Soc Res Meth 10(5), 335-347.

3. Adamson AJ, Griffiths JM, Carlin LE et al. (2003) Proc Nutr Soc 62, 84A.

4. Bradley J, Simpson E, Poliakov I et al. (2016) Nutrients 8(6), 358. 